\title{
CHEMICAL DEFENSE OF AN OZAENINE BOMBARDIER BEETLE FROM NEW GUINEA ${ }^{1}$
}

\author{
By Thomas Eisner 2 , George E. Ball 3 , Braden Roach ${ }^{4}$, \\ Daniel J. ANeschansley ${ }^{5}$, Maria Eisner ${ }^{2}$, \\ Curtis L. Blankespoor ${ }^{2}$, and Jerrold MeinWald ${ }^{4}$
}

We had occasion recently to study 3 live specimens of Pseudozaena orientalis opaca, an ozaenine carabid beetle (subfamily Paussinae, tribe Ozaenini) from New Guinea, and report here on the biology and chemistry of its defensive spray mechanism. A number of New World ozaenines had previously been studied chemically and shown to be "bombardiers" that discharge a hot quinonoid mixture (Aneshansley et al. 1969, 1983; Eisner and Aneshansley 1982; Eisner et al. 1977; Roach et al. 1979). Pseudozaena proved no exception.

\section{Materials AND Methods}

The three Pseudozaena, all males, were taken in Madang Province, Papua New Guinea, by D. H. Kavanaugh, G. E. Ball, and N. D. Penny, on April 6, 1989, at $5^{\circ} 10^{\prime} \mathrm{S}, 145^{\circ} 20^{\prime} \mathrm{E}, 160 \mathrm{~m}$ elevation, in a recently cleared area at the edge of lowland rain forest, at night at UV light, just before a rain storm. The specimens were maintained for weeks in captivity, in a tin can with a shallow layer of soil, on a diet of freshly killed insects (ants, mealworms, caddis flies and various species of two-winged flies). At irregular intervals, the soil was moistened with a small amount of water, either sprinkled on the surface or provided through a small piece of saturated paper towel. Although active at night, the beetles were "comatose" during daylight hours when they acted as if they were dead.

\footnotetext{
'Paper no. 90 of the series Defense Mechanisms of Arthropods. Paper no. 89 is Dussourd et al. 1989, Experientia (in press).

${ }^{2}$ Section of Neurobiology and Behavior, Cornell University, Ithaca, New York 14853.

${ }^{3}$ Department of Entomology, University of Alberta, Edmonton AB, Canada T6G 2E3.

${ }^{4}$ Department of Chemistry and ${ }^{5}$ Department of Agricultural and Biological Engineering, Cornell University, Ithaca, New York 14853

Manuscript received by the editor September 5, 1989.
} 
For purposes of obtaining secretion, the beetles were coaxed into small vials and gently pinched and prodded with forceps until they discharged several times. The yellowish secretion was then immediately rinsed from the vials with methylene chloride as solvent. One such secretion sample per beetle was analyzed by gas-liquid chromatography/mass spectrometry (GLC/MS) (Finnigan model 3300; injection port $150^{\circ} \mathrm{C}$; SPB-1 Supelco column, $50 \mathrm{~m} \times 0.75 \mathrm{~mm} ; 150$ $\mathrm{mL} / \mathrm{min}$. $\mathrm{He}, 75^{\circ} \mathrm{C}$ for $5 \mathrm{~min}$, then $8^{\circ} \mathrm{C} / \mathrm{min}$ increments to $250^{\circ} \mathrm{C}$; ion energy $70 \mathrm{eV}$ ).

Measurements of spray temperature were made by inducing the beetles to discharge upon a calibrated electronic sensing device, such as we used with other bombardiers (Aneshansley et al. 1969, 1983). The Pseudozaena were fastened dorsally to a fixed rod with wax and positioned for observation on the stage of a stereomicroscope. The sensing device was placed within $<1 \mathrm{~mm}$ of the gland opening of one side. Ejections in the direction of the sensing unit were then induced by pinching the beetle's hindleg of the corresponding side. Measurements were made of ejections from both left and right glands of each beetle.

To test for the beetle's ability to aim its spray, the animals were individually affixed to rods, placed on sheets of chemical indicator paper, and caused to spray by pinching individual legs with forceps. Details of this technique, which we used with other bombardies, have been described (Eisner, 1958).

Closeup observation of the beetle's abdomen and of the aiming adjustments that accompany the discharges was effected by tether-

SPECIMEN (body mass)<smiles>O=C1C=CC(=O)C=C1</smiles>

40

32

36<smiles>CC1=CC(=O)C=CC1=O</smiles>

$\mathrm{CH}_{3}\left(\mathrm{CH}_{2}\right)_{13} \mathrm{CH}_{3}$

51

9

50

18

48

16

Table 1. Relative percent of major chemical constituents in defensive spray of the three Pseudozaena males. 
ing the beetles in lateral view on the stage of a stereomicroscope and stimulating them by pinching individual appendages with forceps.

\section{Results AND Conclusions}

Chemistry. The Pseudozaena spray proved to contain three components (1, 4-benzoquinone; 2-methyl-1, 4-benzoquinone; $n$-pentadecane; identified by GLC/MS comparison with authentic samples), in roughly comparable proportions in the three individuals (Table 1). The same chemicals also figured as primary constituents in the spray of all New World ozaenines previously studied (9 Panamanian species) (Eisner et al. 1977; Roach et al. 1979). Additional components present in lesser or trace quantities in some or all of the Panamanian species (3,4-dimethyl-1, 4-benzoquinone, 2-ethyl-1, 4-benzoquinone, further alkanes) appears to be lacking in Pseudozaena.

Spray temperature. The values obtained $(\overline{\mathrm{x}} \pm \mathrm{SD})$ for the three beetles (left and right gland discharges lumped for each) were as follows:

Specimen A: $37 \pm 3^{\circ} \mathrm{C}$ (recorded maximum $\left.40^{\circ} \mathrm{C}\right)(\mathrm{N}=5$ discharges)

Specimen B: $42 \pm 13^{\circ} \mathrm{C}$ (recorded maximum $\left.68^{\circ} \mathrm{C}\right)(\mathrm{N}=9$ discharges)

Specimen C: $50 \pm 18^{\circ} \mathrm{C}$ (recorded maximum $\left.89^{\circ} \mathrm{C}\right)(\mathrm{N}=7$ discharges)

For the one Panamanian species (Goniotropis nicaraguensis) for which comparable thermal measurements had previously been made, mean spray temperature was show to be $65^{\circ} \mathrm{C}$ (recorded maximum $87^{\circ} \mathrm{C}$ ) (Aneshansley et al. 1983).

It was further noted that, in line with what may be true for ozaenines generally, the discharges of Pseudozaena were accompanied by audible detonations.

Aiming ability. Pseudozaena are clearly able to aim their spray. Stimulation of any quarter of the body, or of individual appendages, invariably elicited directed discharges. The spray patterns induced were remarkably similar to those obtained under identical experimental circumstances with the Panamanian Goniotropis nicaraguensis (compare Figs. 1A, B herein, with Figs. 2A, B in Eisner and Aneshansley 1982). The amounts of secretion discharged by 


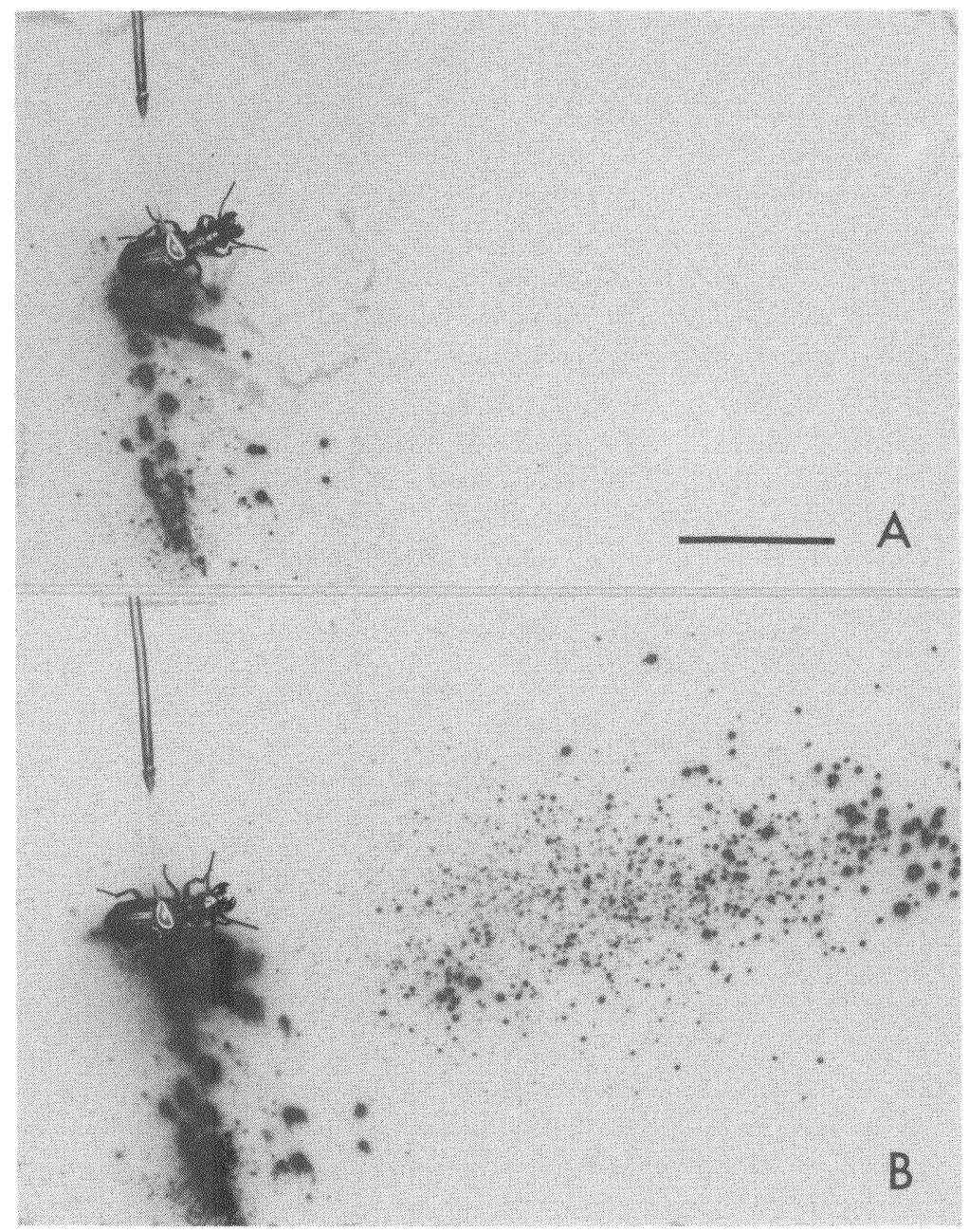

Fig. 1. Spray discharge patterns of Pseudozaena on indicator paper. In A, beetle has discharged in response to pinching of right hindleg with forceps. In $B$, beetle has discharged a second time, in response to pinching of right foreleg. (bar in $A=2 \mathrm{~cm}$ )

Pseudozaena were substantial. Following ejections, targeted areas of the beetle's body were often left visibly contaminated by secretion. The appearance of the secretion varied from yellowish-pasty (immediately after ejection) to crystalline yellow (seconds later). 
Aiming mechanism. Pseudozaena has the typical elytral flanges ("flanges of Coanda") characteristic of Paussinae. In Panamanian ozaenines these flanges had been shown to serve as launching guides for anteriorly aimed ejections of spray (Eisner and Aneshansley 1982). Examination of Pseudozaena, tethered and induced to spray while under observation with a stereomicroscope, showed the flanges of this species to function in identical fashion. Spray directed anteriorly in response to stimulation of forelegs was clearly noted to travel forward along the edge of the flanges. The flanges themselves, following such ejections, were often left contaminated with secretion.

Observation of the motion of the abdominal tip during ejections showed that aiming is achieved in Pseudozaena exactly as had been demonstrated for the Panamanian ozaenine, Goniotropis nicaraguensis (Eisner and Aneshansley 1982). When spraying laterally and downward toward hindlegs, Pseudozaena deflects the abdominal tip downward, so that the gland openings are disengaged from the flanges. When on the other hand the beetle discharges forward, it presses the abdominal tip upward, thereby causing the gland openings to be aligned with the flanges. Pseudozaena also shares with $G$. nicaraguensis the possession of a row of setae on the elytra along the line of emergence of the spray from the flanges (Fig. 2A). In $G$. nicaraguensis these setae take up droplets of secretion after forwardly-directed discharges, droplets that are then defensively distributed by wiping action of the legs (Eisner and Aneshansley 1982). In Pseudozaena, such droplet-retention was also noted (Fig. 2B), but it appeared to occur inconsistently and to involve usually only a portion of the setae. The setae of Pseudozaena are not terminally spatulate as those of Goniotropis (Eisner and Aneshansley 1982) and may for that reason be less suited for droplet retention.

Gland morphology. The glands of Pseudozaena conform to the typical paussine type, such as occurs with little variation in Ozaenini, Paussini, and Metriinae. Gland preparations made by one of us (T.E.) of species from all these groups (Goniotropis nicuraguensis, Ozaena magna, Pseudocerozaena panamensis, Mystropomus regularis, Metrius contractus) are fundamentally similar to that shown here of Pseudozaena (Fig. 3). 

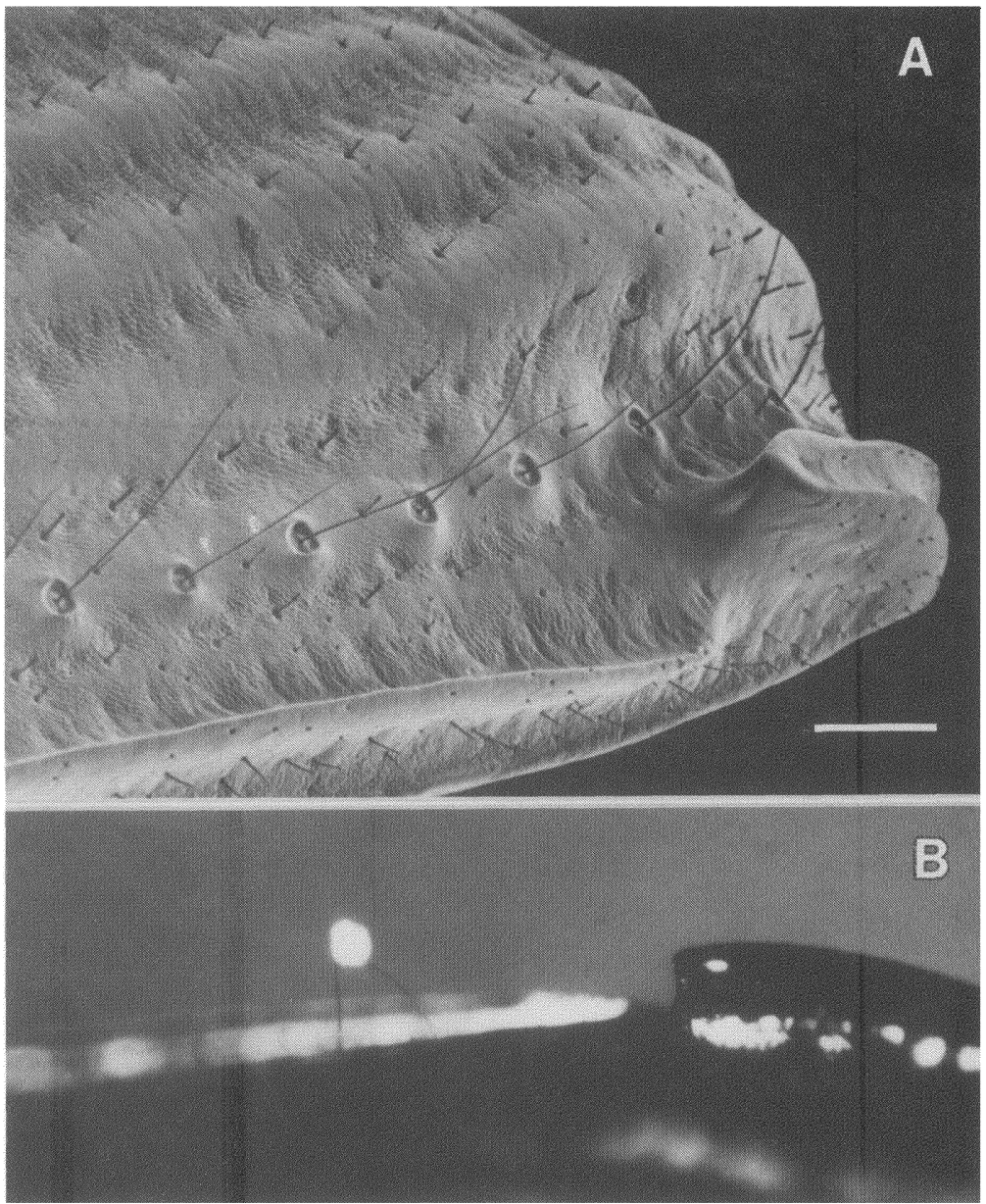

Fig. 2. (A) Posterior half of left elytron of Pseudozaena in oblique view, showing the curved flange ("flange of Coanda") on lower right, and the row of setae aligned along the direction of emergence of spray from flange. (B) Dorsal view of outer margin of right elytron Pseudozaena, photographed immediately following a forwardly-directed ejection of spray. Flange is on right; a droplet of secretion from the spray is seen trapped by a pair of setae. (bar in $A=0.2 \mathrm{~mm}$ ) 


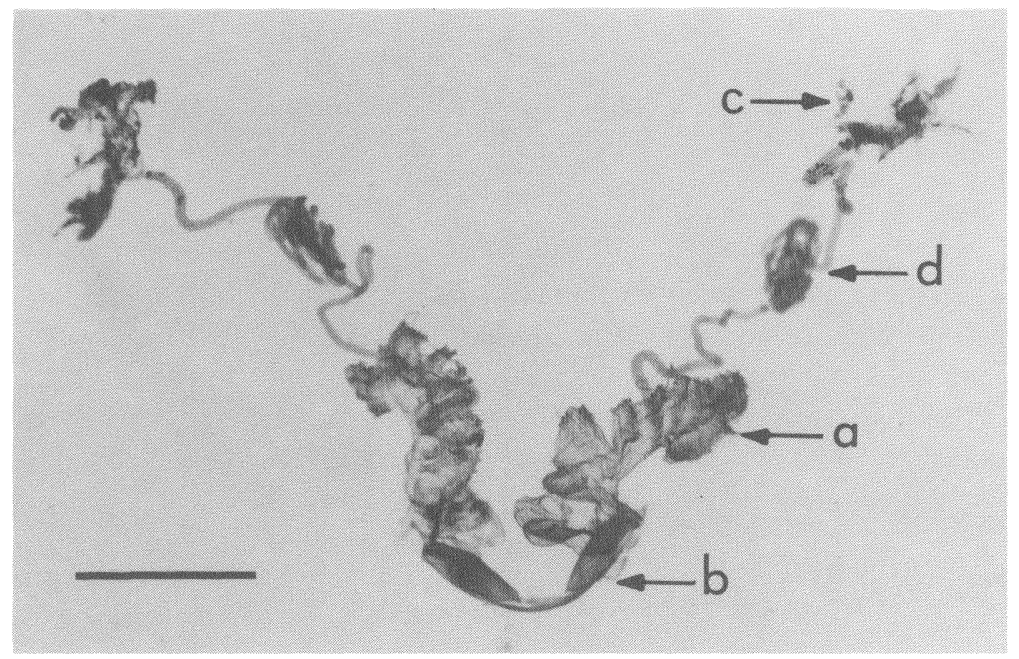

Fig. 3. Glandular apparatus of Pseudozaena. In this KOH-treated preparation only cuticular parts are preserved. As is typical for bombardier beetles, each defensive gland is a two-chambered structure, consisting of reservoir (a) and reaction chamber (b). The glandular tissue that supplies secretion to the reservoir is here denoted by an entangled remnant of cuticular ductules from that tissue (c). The efferent duct connecting the gland tissue to the reservoir undergoes tight coiling about midway along its length (d). (bar $=2 \mathrm{~mm}$ ).

Conclusion. In all major respects-secretory chemistry, structure, and operation - the glandular system of Pseudozaena resembles that of New World ozaenines. Despite such similarity, however, Pseudozaena is not closely related to any of the New World members of the tribe. Rather, it is a derived taxon of a group that includes the Oriental genus Itamus, the Madagascan Spraerostylus, and Afrotropical Afrozaena. The common ancestor of this complex may have shared an earlier common ancestry with the progenitor of some of the New World taxa, a connection that would have been broken no later than Late Cretaceous, when the newly formed Atlantic Basin separated proto-Africa from proto-South America. Thus, one can infer that the defensive system, including the basic compounds secreted by the glands, is at least as old as Late Cretaceous, and probably older because the same defensive system is characteristic of the primitive sister group of the Ozaenini, the Metriini. This inference is supported by the general primitiveness in 
structural features of the metriine-ozaenine stock within the family Carabidae. Thus, the defensive system characteristic of the metriineozaenine-paussine stock exhibits as much stability as is exhibited by the more easily observed structural features of the Coleoptera.

\section{SUMMARY}

The defensive secretion of the New Guinean ozaenine bombardier beetle, Pseudozaena orientalis opaca, contains 1,4-benzoquinone, 2-methyl-1, 4-benzoquinone, and $n$-pentadecane, and is discharged hot. In structure, secretory chemistry, and mode of operation, the defensive glands of this beetle conform closely to those of New World ozaenines previously studied.

\section{REFERENCES}

Aneshansley, D. J., T. Eisner, J. M. Widom, ANd B. Widom. $1969 . \quad$ Biochemistry at $100^{\circ} \mathrm{C}$ : explosive secretory discharge of bombardier beetles (Brachinus). Science, 165: 61-63.

Aneshansley, D. J., T. H. Jones, D. Alsop, J. Meinwald, and T. EisNER. 1983. Thermal concomitants and biochemistry of the explosive discharge mechanism of some little known bombardier beetles. Experientia, 39: 366-368.

EISNER, T. 1958. The protective role of the spray mechanism of the bombardier beetle, Brachynus ballistarius Lec. J. Ins. Physiol., 2: 215-220.

Eisner, T., T. H. Jones, D. J. Aneshansley, W. R. Tschinkel, R. E. Silberglied, AND J. Meinwald. 1977. Chemistry of defensive secretions of bombardier beetles (Brachinini, Metriini, Ozaenini, Paussini). J. Ins. Physiol., 23: 1383-1386.

EISNER, T. AND D. J. ANEShansLeY. 1982. Spray aiming in bombardier beetles: jet deflection by the Coanda effect. Science, 215: 83-85.

Roach, B., K. R. Dodge, D. J. Aneshansley, D. Wiemer, J. Meinwald, and T. EISNER. 1979. Chemistry of defensive secretions of ozaenine and paussine bombardier beetles (Coleoptera: Carabidae). Coleopterists Bull., 33: 17-20. 

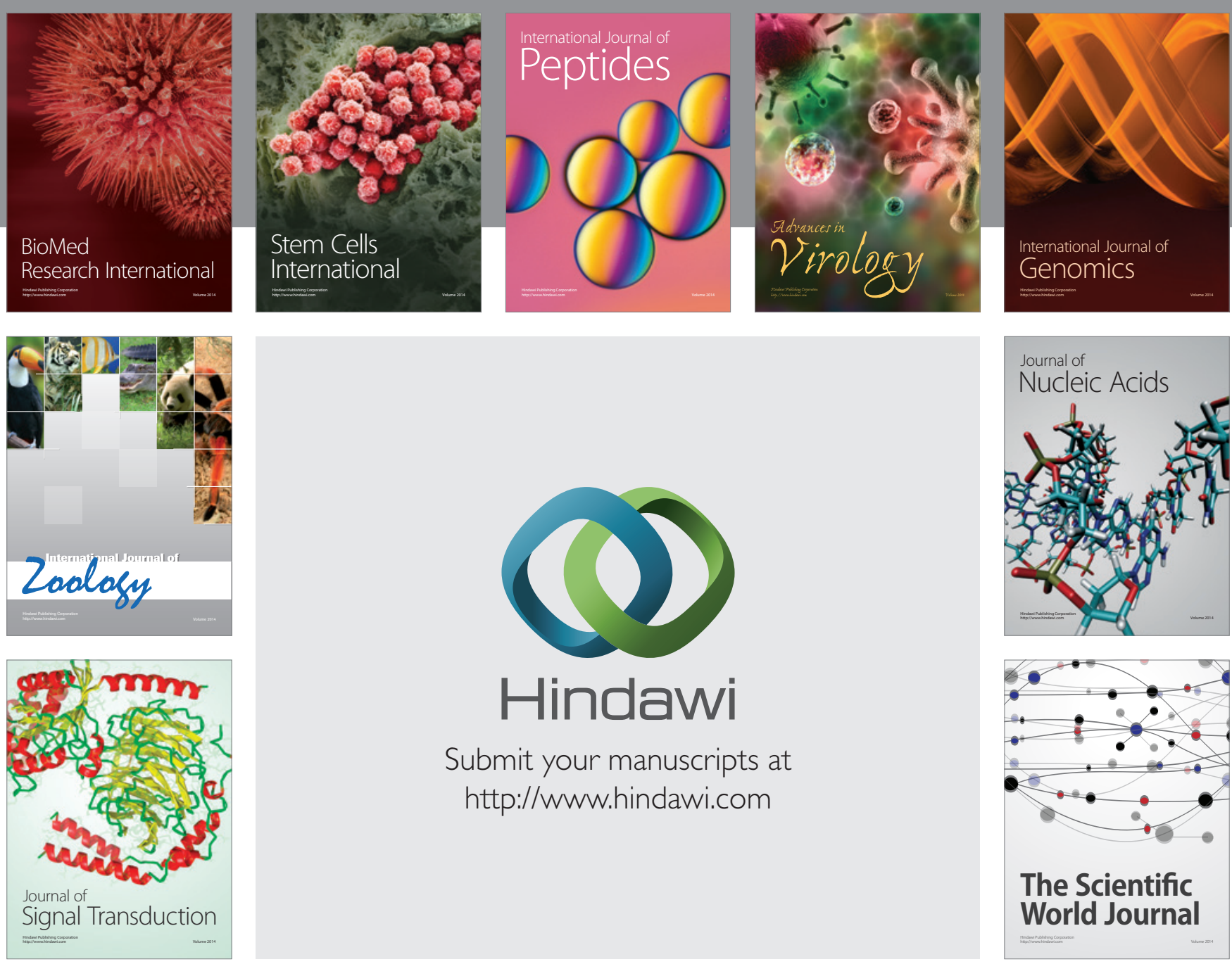

Submit your manuscripts at

http://www.hindawi.com
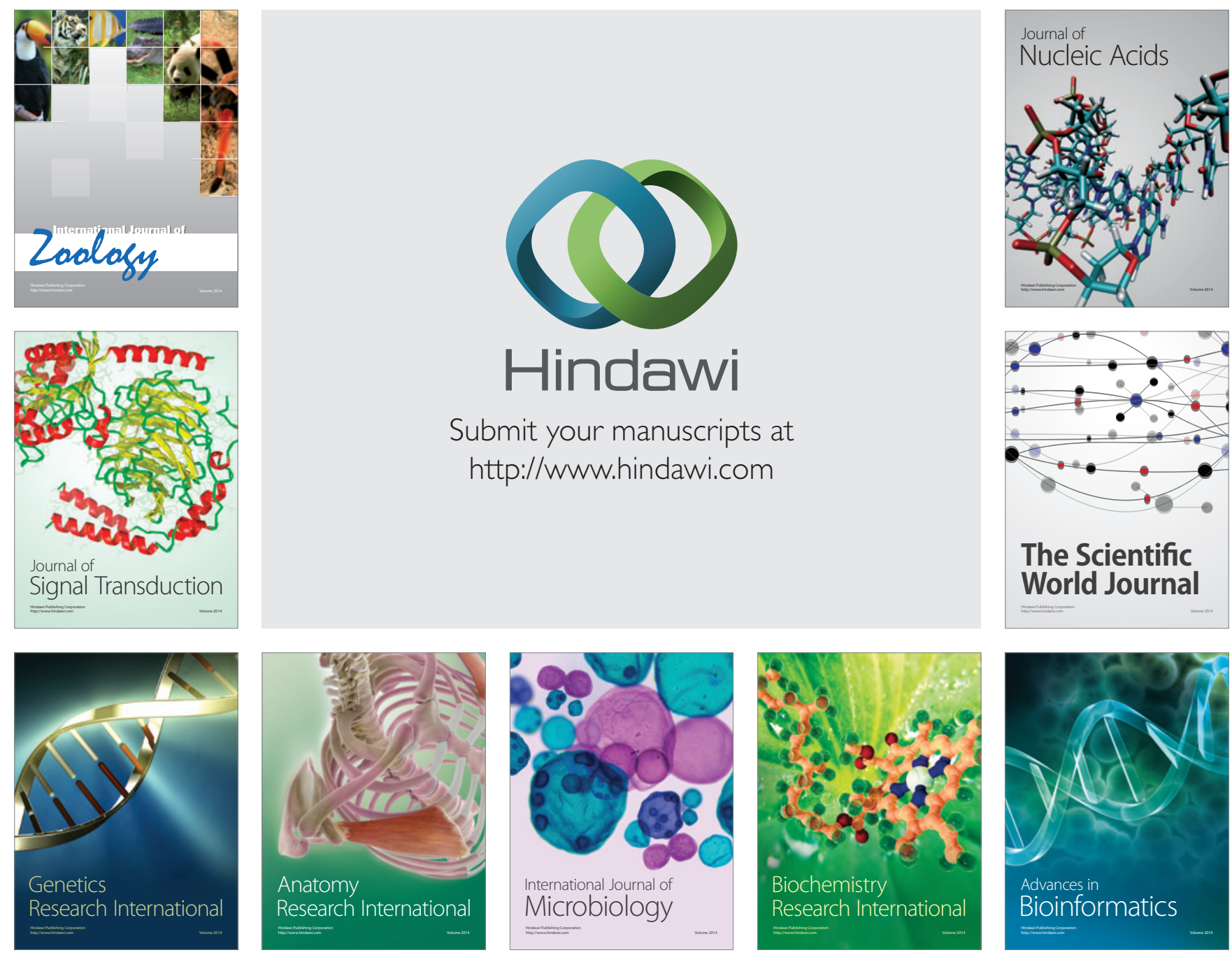

The Scientific World Journal
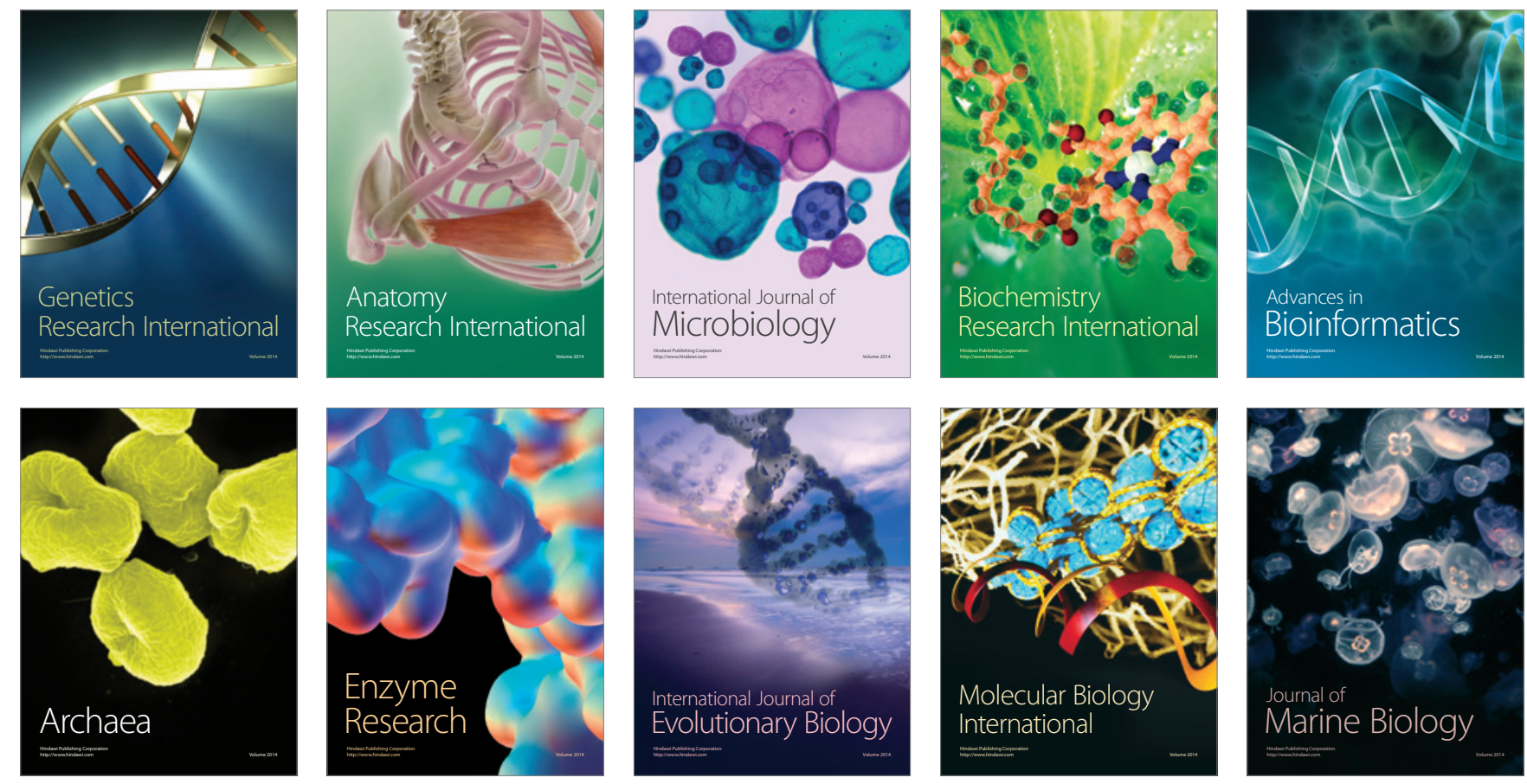